\title{
Necrogeografía de la guerra entre los panteones y las fosas de Sinaloa
}

с

\section{Necro-geography of the War between the Cemeteries and the Graves of Sinaloa}

\author{
Carolina Robledo Silvestre \\ Centro de Estudios e Investigaciones \\ Superiores en Antropología Social \\ México
}

Correo: carolinarobledosilvestre@hotmail.com

https://orcid.org/0000-0002-8686-8323

DOI: 10.481 02/hyg.vi56.352

Artículo recibido: 23/06/2020

Artículo aceptado: I2/10/2020

\section{ABSTRACT}

In this photo essay I share a tour of the cemeteries of northern Sinaloa, as part of my walk with Las Buscadoras of El Fuerte, between 2017 and 2019. From the visual representation of this experience I propose thinking about the forms of inequality in dying and mourning and explore, in the expressiveness of death, the correlation of the political economy that defines this context.

Key-words: Death, Biopower, Cemeteries, Enforced disappearances, Exhumations, Mortuary rituals, Memory.

\section{RESUMEN}

En este ensayo fotográfico comparto un recorrido por los panteones del norte de Sinaloa como parte de mi caminar con Las Buscadoras de El Fuerte, entre 2017 y 2019. A partir de la representación visual de esta experiencia propongo pensar las formas de desigualdad en el morir y el acompañar a los difuntos, y, exploro, en la expresividad de la muerte, el correlato de la economía política que define este contexto.

Palabras clave: muerte, biopoder, panteones, desaparición forzada, exhumaciones, rituales mortuorios. 
Necesitamos volver a introducir la muerte en el discurso para que sea el fundamento dinámico de nuestro combate igualitario. ${ }^{1}$

\section{[15 de agosto de 2018. Panteón Jardines del Bosque, Ahome, Sinaloa]}

Tos panteones imponen un sentido especial al caminar por ¿ellos. Quizá sea la condición atávica de la muerte, colándose en nuestros pies, la que nos conduce a este paso lento, silencioso y afectado. ${ }^{2}$ Aquí, el silencio es más profundo y apenas se perciben las voces de los cuerpos sometidos al "subtierro". Cuerpos que en cualquier momento seremos nosotros.

Estos espacios dominados por la muerte resultan contaminantes, ${ }^{3}$ perturbadores, y etnográficamente desafiantes. ¿Qué lenguaje tenemos para comprender el mundo de los muertos? $\mathrm{Me}$ hago esta pregunta mientras recorro el panteón municipal de Los Mochis, al norte de Sinaloa, con Mirna, líder de Las Buscadoras de El Fuerte. Ella me señala entre la maleza la ubicación de fosas sin nombre que deben marcarse para poder identificar los cuerpos allí inhumados.

Quizá hubiese sido más útil para Mirna estar acompañada por una antropóloga forense o una arqueóloga, cuyas disciplinas están acostumbradas a conversar con las manifestaciones materiales de la cultura y, en particular, con los restos humanos. Yo intento no resbalar entre los montículos irregulares de un territorio inhóspito, y tomo nota rápidamente sobre las cruces que Mirna ha grabado en su memoria como un archivo de la ignominia. Es

${ }^{1}$ Jean Ziegler, Los vivos y la muerte, p. 82.

${ }^{2}$ Baruch Spinoza, Ética demostrada según el orden geométrico. La afección implica que nuestro cuerpo está constituido por el cuerpo exterior.

${ }^{3}$ Mary Douglas, Pureza y peligro. Un análisis de los conceptos de contaminación $y$ tabú. La autora argumenta que la suciedad y la contaminación son sistemas simbólicos asociados con las ideas de orden y desorden. El contacto con lo contaminante amenaza el orden imaginario o simbólico. 
difícil advertir a simple vista las tumbas que señala, pero poco a poco se van haciendo evidentes ante mis ojos como repositorios de vidas apagadas a las que les ha sido negado un entierro digno.

Ésta no es una exploración programada, como ocurre casi todo el tiempo en esta etnografía tejida de emergencias y discontinuidades. El plan inicial era visitar un terreno que el ayuntamiento local había prometido a este grupo de mujeres para construir algo que ellas han decidido llamar "El Pueblito", un panteón para inhumar los cuerpos sin identificar adoptados y cuidados por ellas hasta que puedan ser restituidos a sus familias. Acierto a dibujar un esquema en mi diario de campo que nos permita hacer un conteo somero del problema. Con estos números Mirna iría a hablar con las autoridades encargadas de procurar el espacio para hacer posible el sueño de El Pueblito.

El recorrido que aquí narro forma parte de una investigación etnográfica de largo aliento que inició en el año 2016, cuando viajé por primera vez al norte de Sinaloa a conocer a Las Buscadoras de El Fuerte. Durante tres años mantuve la regularidad de estos viajes acompañada por mis colegas del Grupo de Investigaciones en Antropología Social y Forense (GIASF). En el marco de este proceso promovimos actividades de investigación colaborativa que incluyeron talleres sobre la búsqueda de personas desaparecidas, el desarrollo y publicación de un libro de historias de vida de las buscadoras ${ }^{4}$ y el diseño metodológico de dos bases de datos que hoy son parte de la metodología de documentación de este colectivo.

La etnografía nos ha permitido navegar en este mundo de heridas abiertas y construcción de comunidades en torno a los efectos de la violencia, con la sensibilidad ética necesaria. Al mismo tiempo ha sido una metodología útil para comprender

\footnotetext{
${ }^{4}$ Aida Hernández y Carolina Robledo, Nadie detiene el amor. Historias de vida de familiares de personas desaparecidas en el norte de Sinaloa, Ciudad de México, unAM-Instituto de Investigaciones Jurídicas, 2020.
} 
la violencia desde los matices que planean los sentidos y las prácticas propias de las comunidades y los sujetos que la viven. Esta etnografía se ha nutrido de las epistemologías feministas que insisten en el carácter situado del conocimiento ${ }^{5}$ y la reflexibilidad constante sobre nuestro propio ser en el proceso de investigación: nuestras emociones, nuestro posicionamiento político $y$, sobre todo, las relaciones de poder que se ejercen en el campo.

La etnografía ha sido también una metodología sensible a los asuntos de la muerte en contextos de guerra y conflicto, ${ }^{6}$ pues ofrece una interpretacion del fenómeno desde sus aspectos subjetivos, las lógicas y racionalidades que subyacen a la muerte violenta y las prácticas, hábitos y símbolos producidos desde las colectividades para hacer frente al tabú que ésta implica.

Siguiendo mi recorrido por el panteón de El Fuerte noto cómo las tumbas sin nombre son especialmente perturbadoras. Afectadas de modo radical por la violencia, expresan el desprecio con el que se trata a ciertos cuerpos y nos recuerdan que el morir no es una experiencia igual para todos.

En mis visitas más recientes por los panteones y las fosas clandestinas del norte de Sinaloa me he visto interpelada de manera especial por la distribución desigual de la dignidad cuando se trata de morir y de acompañar a nuestros muertos.

Entre sus itinerarios de indagación, Las Buscadoras han recorrido panteones y fosas sin nombre, ya sea para recuperar los cuerpos que fueron inhumados sin identificar o para ofrecer los ritos funerarios finales a aquellos que se les ubica en su destino final.

${ }^{5}$ D. Haraway, Ciencia, cyborgs y mujeres. La reinvención de la naturaleza; e Id., Modest_Witness@Second_Millennium.FemaleMan_Meets_OncoMouse:Feminism and Technoscience.

${ }^{6}$ Isaías Rojas-Pérez, Mourning Remains State Atrocity, Exhumations, and Governing the Disappeared in Peru's Postwar Andes, Standford, Standford University Press, 2017; Elsa Blair, Muertes violentas: la teatralización del exceso, Medellín, Editorial Universidad de Antioquía, 2005; y Gloria Inés Peláez, Impacto de la violencia en los cuerpos físicos y sociales de las víctimas. Contaminación simbólica de la muerte, Colombia, Universidad Nacional, 2016. 


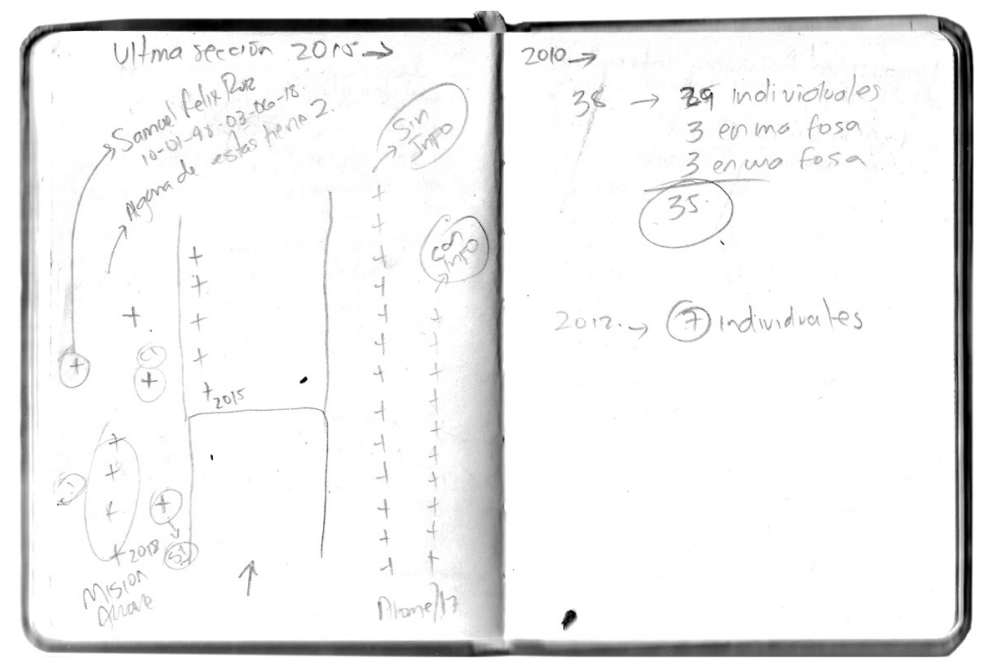

1.Extracto del diario de campo. Panteón Jardines del Bosque, Ahome, Sinaloa. 15 de agosto de 2018 .

Mis pasos por los panteones del norte de Sinaloa han estado siempre acompañados por ellas, sus palabras, sus saberes y sus abrazos.

Antes de conocer a Las Buscadoras ya había iniciado un paseo por la muerte como tema de investigación en Tijuana, donde recorrí panteones, funerarias y epitafios, con una curiosidad más existencial que académica. Es difícil transitar por estos temas sin sentirse profundamente afectada y sin conectar preguntas personales con curiosidades teóricas.

No puede ser coincidencia que dos antropólogos, como Renato Rosaldo $^{7}$ y Finn Stepputat, ${ }^{8}$ produjeran teorías sociales potentes después de sufrir la pérdida fatal de sus parejas. En el caso de Rosaldo, ${ }^{9}$ la experiencia ambivalente de sufrimiento y ra-

\footnotetext{
${ }^{7}$ Renato Rosaldo, Cultura y verdad, nueva propuesta de análisis social.

${ }^{8}$ Finn Stteputat, Governing the Dead: Sovereignty and the Politics of Dead Bodies. ${ }^{9}$ Rodrigo Díaz Cruz (ed.), Renato Rosaldo: ensayos en antropología crítica, México, Casa Juan Pablos/Fundación Rockefeller/Universidad Autónoma Metropolitana-Iztapalapa, 2006 (Estudios Transnacionales).
}

Necrogeografía de la guerra entre los panteones y las fosas de Sinaloa / I 75 
bia que experimenta con la muerte de su primera esposa -Michel Rosaldo-, lo lleva a acercarse a las etnografías sobre los rituales de muerte con una perspectiva crítica y a reconocer que la vida es ambigua, espontánea y posee un alto grado de improvisación, configurando una teoría antropológica que cuestiona la idea de cultura como sistema homogéneo y estático. Por su parte, Stepputat inicia la introducción de su libro Governing the Dead: Sovereignty and the Policits of Dead Bodies con una descripción sobre las horas que siguieron a la muerte de su esposa, las preguntas de los oficiales que llegaron a su casa después de recibir la llamada de emergencia y el despliegue del Estado en la administración del cuerpo de su cónyuge difunta. A partir de esta experiencia Stepputat teje toda una reflexión en torno a la soberanía sobre los muertos: la necropolítica, que será retomada más adelante en este artículo.

Guadalupe Posada, grabador popular mexicano de inicios del siglo $\mathrm{xx}$, que tuvo como protagonista central de su obra a la muerte, produjo a través de ella una postura crítica a la aristocracia porfirista de la época. Sus esqueletos señalaban la miseria y las injusticias producidas por esta clase, que a pesar de sus pretensiones de eternidad sufría por igual la fatalidad de la muerte. Con sus esqueletos que bailan, cantan, montan a caballo, hacen declaraciones de amor, asisten a parrandas, pelean y rebosan de alegría, José Guadalupe hizó una crítica aguda al poder de la época. ${ }^{10}$

La idea de igualdad frente a la muerte -como destino comúnresulta políticamente potente, pero incompleta para asomarnos a la realidad del morir desde una antropología que devele las estructuras de desigualdad. En esa pretensión se inscribe este ensayo.

\footnotetext{
${ }^{10}$ Guadalupe Ríos de la Torre, “José Guadalupe Posada. Un cronista de la época porfiriana”, pp. 107-119.
} 
En el contexto sinaloense se han documentado ya bastantes ejemplos de la expresividad de la muerte: los panteones palaciegos en donde reposan los restos de "los narcos"11 los más de 2000 cenotafios instalados en las vías principales, plazas o rincones citadinos en donde se recuerda a quienes fueron asesinados, ${ }^{12}$ y la exposición de cuerpos como mensajes que producen memorias de terror en los espacios públicos.

La elocuencia expresiva de estas marcas espaciales nos recuerda que la vida post mortem no es ajena a las condiciones de poder $\mathrm{y}$ que, al contrario, la constituyen. Estos símbolos funerarios son, en todos los casos, manifestaciones de una economía política tanto material como simbólica- del tratamiento de los cuerpos. ${ }^{13}$

También en la muerte reside el poder, también en la muerte hay cuerpos expuestos a la precariedad y al olvido, y otros que son motivo de culto y devoción. Estas formas de expresión política en el campo de la muerte configuran una necrogeografía expresada en relaciones de desigualdad, dominación, exclusión y resistencia que se hacen materialmente evidentes en el espacio de los panteones, a través de procesos de segregación, clasificación y borramiento.

${ }^{11}$ Eloy Méndez Sáinz, "De anti-lugares, o la difusión de la narco arquitectura en Culiacán”, pp. 43-62.

${ }^{12}$ Durante el Encuentro Memoria y memoriales en México, llevado a cabo el 14 y 15 de enero de 2020 en El Colegio de México, Eugenia Allier presentó su ponencia "Entre la violencia estatal y la violencia delincuencial: una comparación entre cuatro lugares de memoria en México", en la que refirió la existencia de al menos 2800 cenotafios distribuidos en la zona urbana de Culiacán. Uno de los más emblemáticos de la ciudad es el de Edgar Guzmán, hijo del conocido narcotraficante el Chapo Guzmán. Este cenotafio además de estar decorado con flores frescas de manera permanente, es constantemente vigilado por grupos de hombres con la misión de protegerlo. Véase: <https://www.debate.com.mx/culiacan/Ponen-decoraciones-navidenas-en-cenotafio-de-hijo-del-Chapo-en-Culiacan-20191211-0138.html>.

${ }^{13}$ Sévane Garibian, Élisabeth Ansttet y Jean-Marc Dreyfus, "Introducción”, en Restos humanos e identificación. Violencia de masa, genocidio y el "giro forense", pp. 9-20. 
La forma en que se manifiesta la política sobre los muertos revela que la muerte no es el límite del (bio)poder moderno: "no es necesario buscar un punto histórico de conexión entre los poderes de la vida y la muerte porque juntos son constitutivos del carácter sagrado de la comunidad política". ${ }^{14}$

Los panteones, en particular, gozan de un lenguaje elocuente que implica marcas producidas en el espacio a partir de la economía política de la muerte. En la antigua Grecia, por ejemplo, todo ciudadano tenía derecho a un epitafio donde figuraran los datos de filiación y el lugar donde había muerto. Ese derecho fue denominado "derecho a la muerte escrita" y estaba relacionado con el papel de la escritura como soporte de la identidad y de la humanidad. ${ }^{15}$ Así, a través de la palabra se elaboraba la condición humana de los difuntos.

Cuando ese lugar de humanidad dado por la palabra no está dispuesto, como en el caso de la desaparición de personas o la inhumación de cuerpos sin identificar, nos encontramos frente a una "muerte desatendida"16 o una "mala muerte", que implica la condición de liminalidad de quienes habitan un umbral por fuera del orden de lo humano.

La antropología nos enseña que las sociedades humanas, más allá de sus diferencias culturales, se caracterizan por las clasificaciones que ordenan el mundo, dentro de las cuales la "buena muerte" y la "mala muerte" tienen un lugar esencial. En condiciones de buena muerte el difunto es acompañado en su tránsito por prácticas de despedida y separación, en donde se incluyen los tratamientos correctos sobre los cuerpos y el acompańamiento de los deudos. Se busca así sellar una nueva relación con los difuntos,

${ }^{14}$ Steputtat, Governing the Dead, op. cit., p. 18.

${ }^{15}$ María Victoria Pita, Formas de morir y formas de vivir. El activismo contra la violencia policial.

${ }^{16}$ Laura Panizo, "Cuerpos desaparecidos. La ubicación ritual de la muerte desatendida”, pp. 17-40. 
de ahora en adelante invisibles, aunque no del todo ausentes, de la vida de sus familiares.

La "mala muerte", por su parte indica las muertes violentas o disruptivas, que no se enfrentan a través de las prácticas prescritas, o en donde el tratamiento del cuerpo se considera inadecuado, fuera de lugar. Una mala muerte puede entonces hacer referencia tanto a la circunstancia específica del deceso, como al tratamiento del cadáver (o a la ausencia de éste) y a la práctica ritual en general.

Las tumbas con cuerpos no identificados guardan la "mala muerte", la muerte desatendida, que no ha sido reconocida socialmente, ritualizada, ordenada. Esta muerte desatendida está por fuera del proceso social que implica el morir en condiciones de normalidad.

"Tierra Santa" se llama este panteón ubicado en Batamote, un pequeño poblado ejidal tomado por los grupos armados hace años. Lo recorrimos con la mamá y el papá de Juan Carlos, un joven de 19 años que desapareció en este pequeño ejido y fue

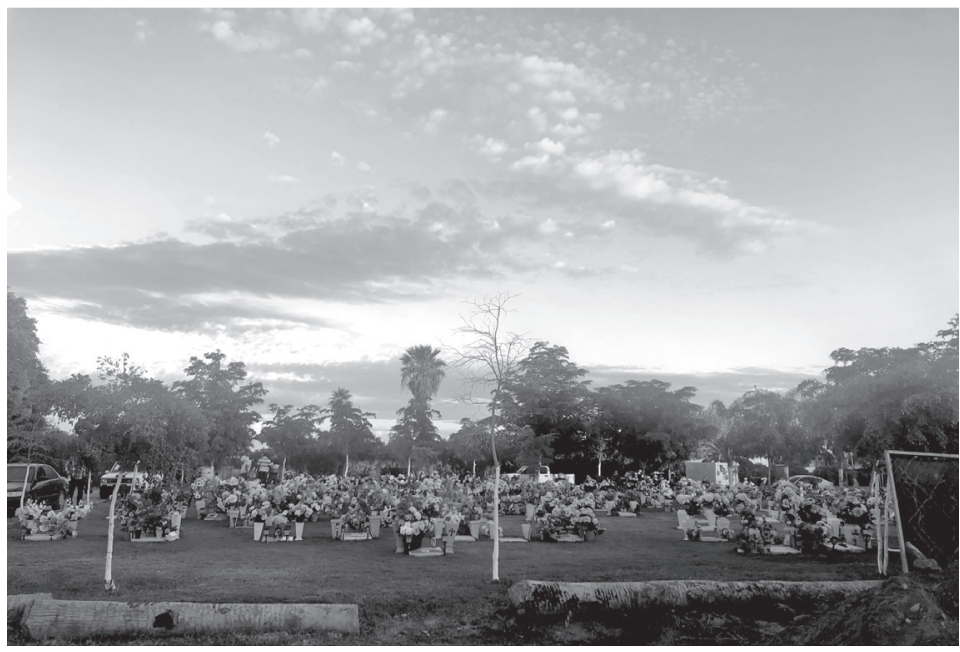

2. Tierra Santa, panteón ubicado en Batamote, ejido Benito Juárez, municipio de Guasave, Sinaloa. Archivo propio, 2018.

Necrogeografía de la guerra entre los panteones y las fosas de Sinaloa / I79 


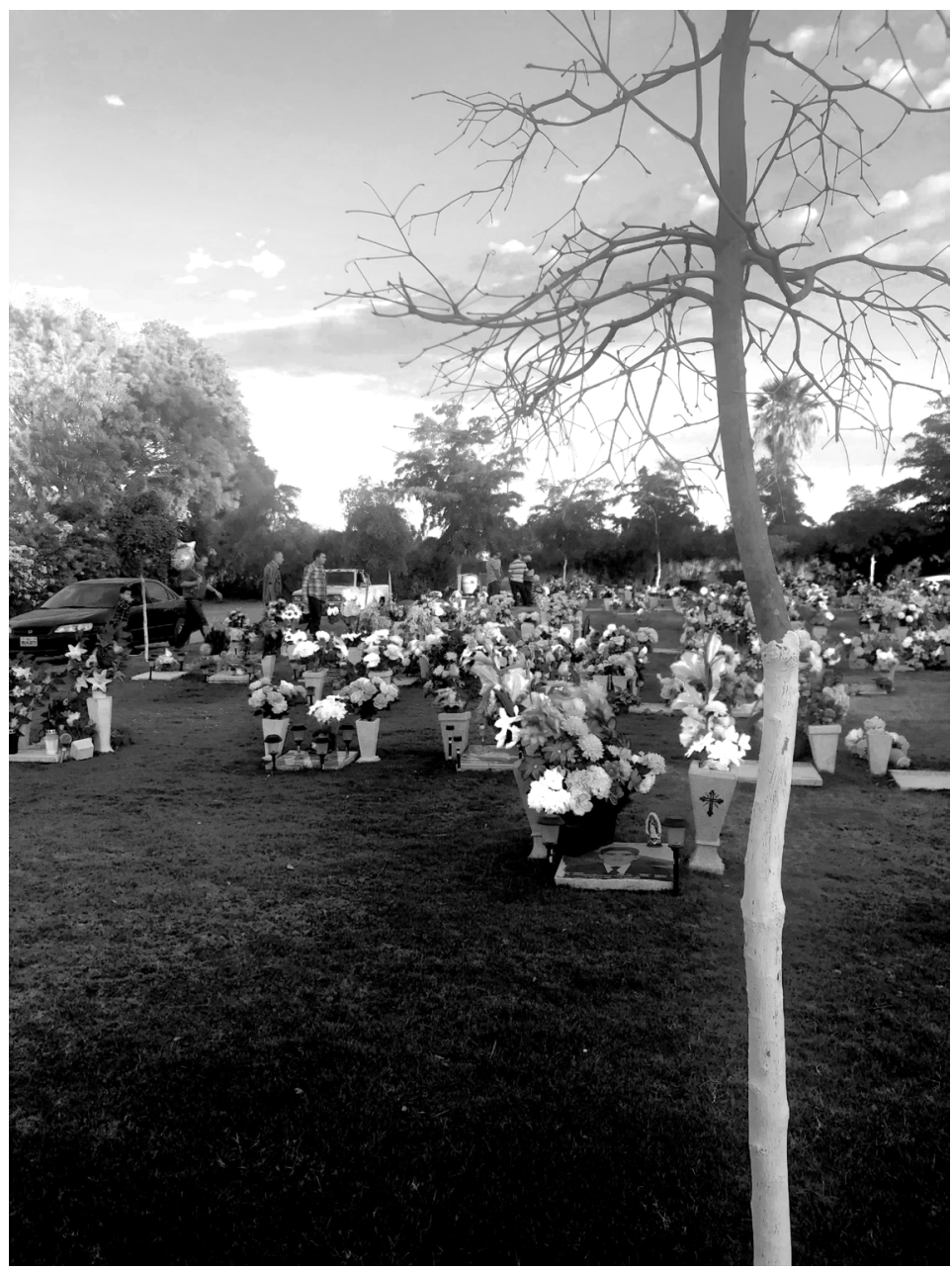

3. En Tierra Santa las fotos de los jóvenes asesinados son un paisaje cada vez más común. Batamote, ejido Benito Juárez, municipio de Guasave, Sinaloa. Archivo propio, 2018.

hallado dos años después a kilómetros de distancia en una fosa clandestina. Felícitas y Luis me cuentan, mientras recorremos las tumbas, que la mayoría de los cuerpos inhumados en el panteón son de jóvenes asesinados como Juan Carlos. Cuerpos expuestos 


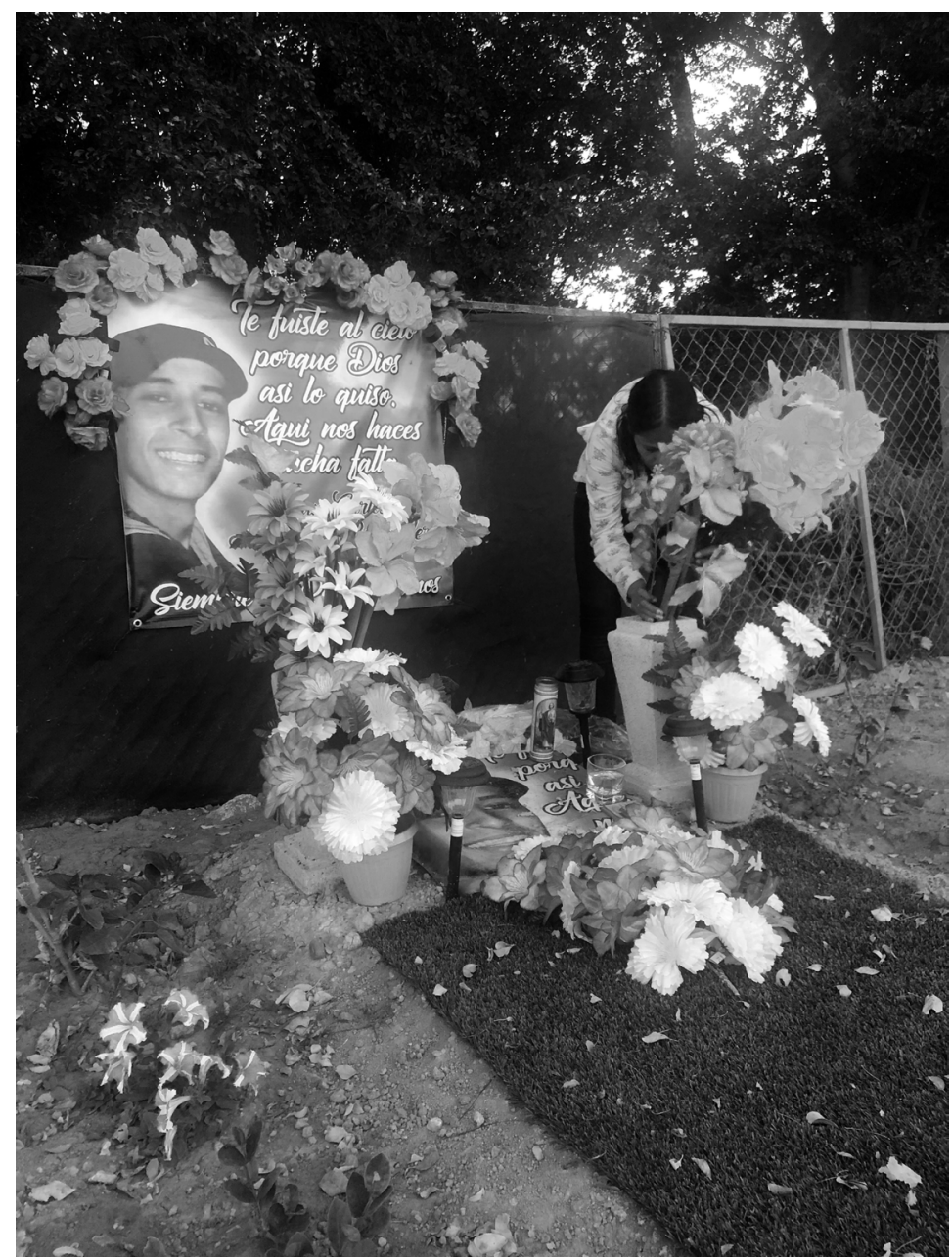

4. Juan Carlos, desaparecido en 2015 y recuperado en 2017, ahora descansa en el panteón Tierra Santa del pequeño poblado donde nació y creció. Archivo propio, 2018.

a un estigma letal, que hoy, en su condición de vidas perdidas, configuran un paisaje desolador frente al futuro.

Aquí la geografía de la muerte demarca un horizonte histórico irregular: ahora no son los viejos los que yacen bajo la tierra de es-

Necrogeografía de la guerra entre los panteones y las fosas de Sinaloa / I8I 


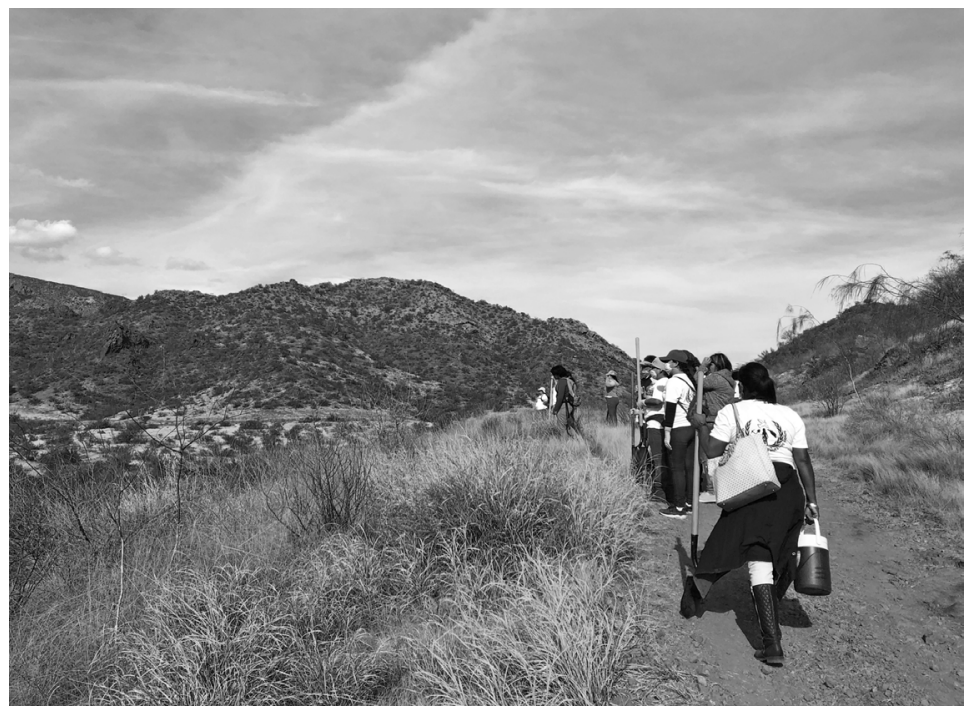

5. La búsqueda de fosas conduce generalmente a paisajes agrestes en donde las buscadoras despliegan todos sus saberes sensoriales para encontrar los enterramientos clandestinos. Archivo propio, 2017.

tos pueblos agrícolas abandonados por el Estado. Son los cuerpos jóvenes los que pueblan el territorio de los ancestros, y sus padres e hijos los que lloran su ausencia.

Felícitas, la madre de Juan Carlos, se incorporó al grupo de Las Buscadoras de El Fuerte para buscar a su hijo, y hoy es una de las "afortunadas" que viste la camiseta verde con la leyenda "Promesa cumplida", mientras que muchas de sus compañeras aún usan la de color negro estampada con la frase "Te buscaré hasta encontrarte".

Todos los días, antes de abrir su negocio en el centro de Batamote, Felícitas visita el panteón, riega las plantas que rodean la tumba de su hijo, acicala cada rinconcito de este territorio recuperado para su cuerpo, quita el polvo y conversa con su muchacho. Todos los meses su familia debe pagar, a la empresa que administra el panteón, una renta para garantizarle este lugar a su hijo, evitando que sea trasladado a la fosa común. 
Ella desconoce las coordenadas del lugar donde encontró a su hijo; se siente desorientada cuando intenta dar las indicaciones para llegar a ese territorio hostil que lo albergó clandestinamente en su primer entierro, ese espacio que tal vez guarda el misterio de los últimos momentos de su vida. Después del hallazgo ha visitado, junto con sus compañeras buscadoras, esta tumba clandestina de la cual recuperó el cuerpo de su hijo. En una de sus visitas instaló una cruz y en otra aprovechó las flores y las veladoras que la acompañaban.

Las fosas clandestinas marcan la necrogeografía del abandono, espacios límite en donde se revela la fragilidad de la vida y la capacidad de dańo de quienes detentan el poder de dar muerte. Su dominio territorial no se manifiesta nada más en el control de las calles, las esquinas y las tierras que demarcan la soberanía del más fuerte, también está en el mapa de las fosas que marca su maquinaria de muerte.

Ubicadas en medio de la diversidad paisajística de esta región, estas fosas no son, sin embargo, sólo silencio. A través de un lenguaje propio comunican su existencia a Las Buscadoras, expertas en interpretarlo. Ellas observan,

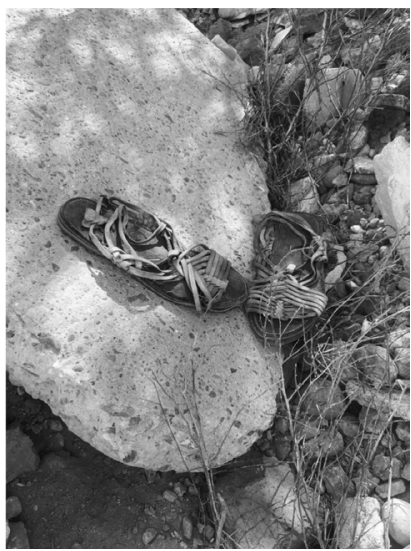

6. Guaraches en el campo. Señales en la búsqueda de "tesoros". Archivo propio, 2017. escuchan, huelen y desentierran con paciencia pequeñas señales con el único propósito de devolver la dignidad de los cuerpos abandonados al arbitrio de la naturaleza.

Hay zonas prohibidas para quienes buscan. Territorios en los que recuperar cuerpos expone seriamente al peligro. Las fosas clandestinas, al fin y al cabo, son una manifestación del poder que tienen un correlato en la economía política de estos territorios. La confiscación y el ocultamiento de 


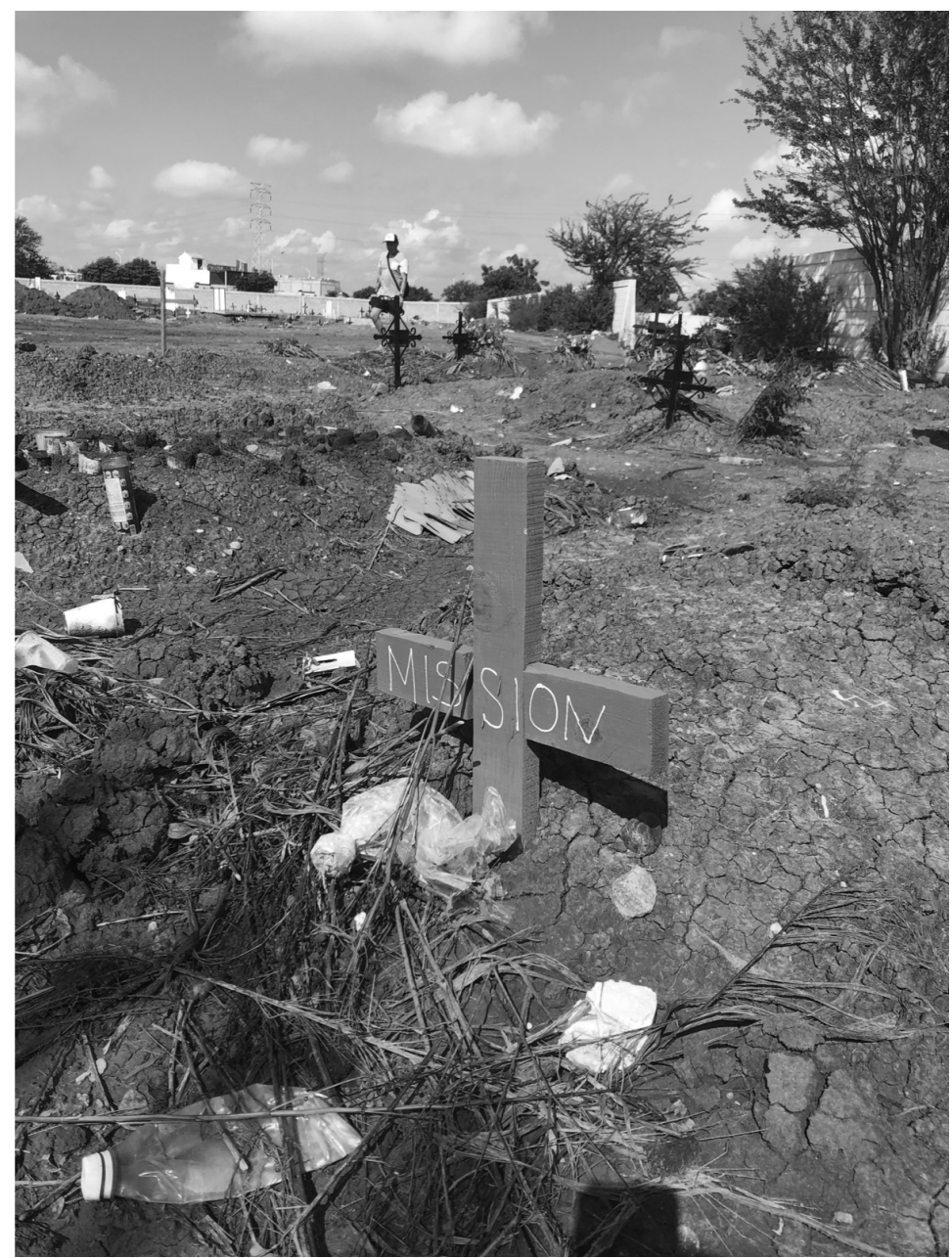

7. Tumbas de personas no identificadas en el panteón Jardines del Bosque, Ahome, Sinaloa. Archivo propio, 2018

los cuerpos cumplen una función comunicativa deliberada y manifiestan el carácter sistemático del aparato "desaparecedor", que materializa el poder de dar muerte y suspender el derecho de duelo.

De las fosas clandestinas nos movemos hacia las fosas comunes del estado, siguiendo la ruta de Las Buscadoras, quienes exploran 
allí el rastro de los no identificados. Ubicadas en los márgenes, las esquinas o los corredores que sobran en el panteón municipal, estas fosas nos ponen frente a un régimen de desigualdad espacial y social elocuente.

Las fosas comunes, tradicionalmente dispuestas para el entierro de los pobres, los olvidados y los "racializados", ${ }^{17}$ se encuentran fuera de las zonas privilegiadas del panteón en donde actúa "la mágica inserción de los santos, de las reliquias o de algún ademán clerical". ${ }^{18}$ Entierros por fuera de lo sagrado, cuerpos asignados al dominio de las funerarias privadas, el orden policial y la indigencia, que reproducen un tipo de apartheid funerario expresado en la clasificación de cuerpos dispuestos con desprecio bajo la tierra. ${ }^{19}$ En estos panteones comunes se materializan las políticas de muerte contra cuerpos específicos, cuerpos que se siembran en masa, en un acto de devaluación producido por el sistema liberal de mercado. Allí radican los que no tienen valor, los que buscan ocultarse, los abandonados.

Las tumbas más precarias en este panteón no tienen lápidas ni cemento, sólo un montículo de tierra sobre el que se levanta una cruz con datos generales: número de investigación ministerial, nombre del agente del ministerio público encargado y, a partir de hace poco, nombre de la funeraria privada que realizó el levantamiento. Lo que allí sucede está vinculado con un sistema burocrático que ejerce las órdenes de inhumación, exhumación e investigación de los casos, pero también de empresas privadas que lucran con el carácter masivo de la muerte.

La soberanía sobre los muertos no es exclusiva del estado. En Sinaloa, como en otras entidades federativas, las empresas funerarias compiten por obtener la propiedad temporal de los muertos ante las llamadas de emergencia que indican la presen-

${ }^{17}$ G. Denyer, Willis, "The Potter's Field”.

${ }^{18}$ Ziegler, Los vivos y la muerte, op. cit., p. 178.

${ }^{19}$ Nicky Rousseau, "Identificación política, disciplinas: personas desaparecidas y esqueletos coloniales en África del Sur”, pp. 163-190. 
cia de un cadáver. Sus servicios son una subrogación por la que el Estado paga al externalizar el cuidado de los muertos por fuera de toda posibilidad de garantía judicial sobre el proceso. De este modo las fosas comunes en donde estas funerarias disponen finalmente de los cuerpos expresan también la oscura lógica de la violencia liberal del abandono de la que participan el Estado y el mercado. ${ }^{20}$

Estas geografías exponen el silencio, la no identidad, los cuerpos nudos, carne y hueso, cuerpo de nadie. Son los llamado NN -Noche y Niebla, No Name-, los sin nombre, un "des-significante", un "no lugar" que provoca en la sociedad una atadura al discurso que oculta crímenes y castiga la vida: "tú aquí no eres nadie", "no tienes nombre", "no estás ni vivo ni muerto", "no existes".

Aquí no hay un nombre que remita

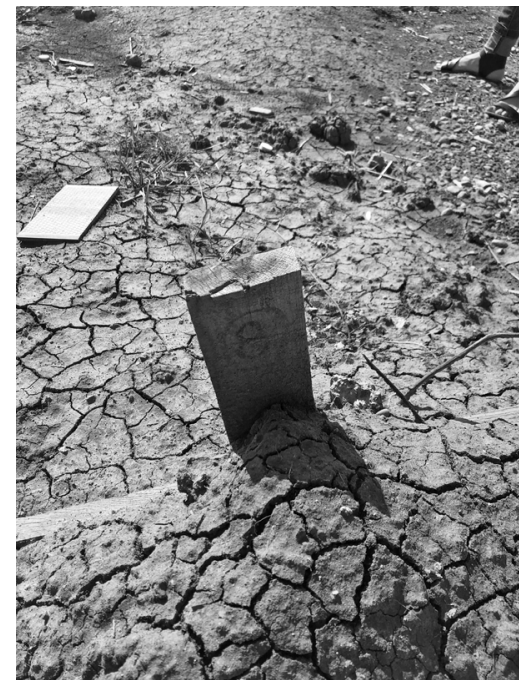

8. Después de un periodo de lluvias intensas, las fosas comunes sufrieron de inundaciones que dificultan identificar su ubicación. Jardines del Bosque, Ahome, Sinaloa. Archivo propio, 2018 a una vida, ni quien acicale con amor el espacio; sólo números en clave judicial que apuntan a una carpeta, por seguro abarrotada junto a muchas otras en un anaquel del olvido, infraestructura fundamental del régimen de impunidad que sostiene esta guerra. Las inundaciones, la intensidad del calor y el paso del tiempo tienen consecuencias devastadoras para estos cuerpos solitarios. La referencia escrita, frágil desde el inicio, desaparece, haciendo ilegible lo que allí habita. Algunos de los cuerpos que reposan en estos intersticios del panteón municipal han sido recuperados de las fosas clandestinas y después enterrados de nuevo, ahora bajo custodia del Estado, extendiendo su calidad de abandonados.

${ }^{20}$ Willis, "The Potter's Field", op. cit., p. 563. 
[28 de noviembre de 2018. Panteón Jardines del Bosque,

Ahome, Sinaloa]

Visitamos una vez más el panteón municipal con Las Buscadoras.

La familia de Felipe, un muchacho del pueblo indígena yoreme, desaparecido junto a otros tres jóvenes meses atrás, espera su exhumación junto a una tumba sin lápida. A pesar de que se acerca el invierno, el sol nos castiga con toda su fuerza en este mediodía terroso y seco.

Las hermanas de Felipe están a unos pasos del lugar donde los panteoneros han iniciado la inhumación con una pala y un pico. La espera empieza a hacerse insoportable. Por alguna razón uno de aquéllos no encuentra el cuerpo del muchacho donde marca la tumba. A su alrededor, un grupo de hombres de la Procuraduría General de Justicia del Estado se asoma curioso, y rápidamente vuelve a protegerse del sol, mientras las mujeres aguardan al lado de la familia.

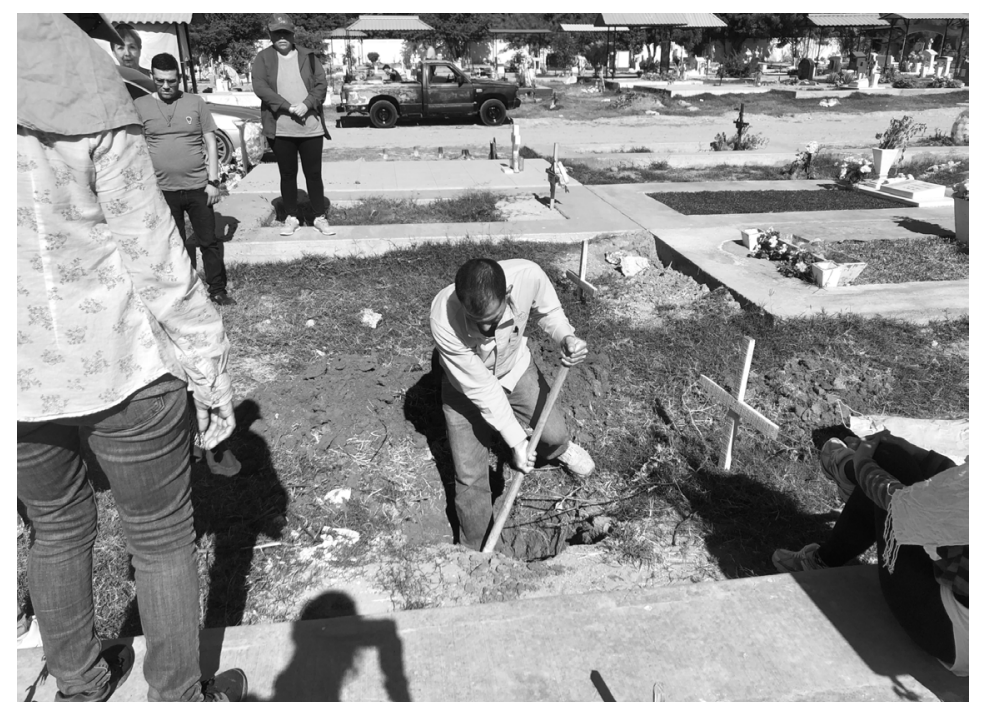

9. Los panteoneros trabajan para recuperar el cuerpo de Felipe. Horas pasan antes de que su familia pueda reencontrarse con los restos de su cuerpo conservados en una bolsa negra. Archivo propio, 2018.

Necrogeografía de la guerra entre los panteones y las fosas de Sinaloa / 187 
Más de una hora después del infructuoso esfuerzo del panteonero, Mirna empieza a darle sugerencias para la excavación y, con su ayuda, logra detectar lo que buscaba. Esta larga y silenciosa espera es interrumpida sólo a veces por el sollozo de la hermana de Felipe, que no deja ni un minuto de seguir con sus ojos cada movimiento del joven que sacará el cuerpo de su hermano de la tierra.

De repente, ese sollozo se convierte en grito cuando frente a sus ojos aparece el terror que revela la profundidad de esta descuidada tumba. Nada de lo que allí ve le recuerda a su hermano, a su niño, como le llama.

Felipe había desaparecido meses atrás. Murió asesinado junto con otros dos jóvenes de la comunidad que fueron hallados con posterioridad por Las Buscadoras. A sus cuerpos se les practicó la prueba genética, un logro del colectivo después de años de obligar al Estado a hacerlo con todos los cadáveres sin identificar

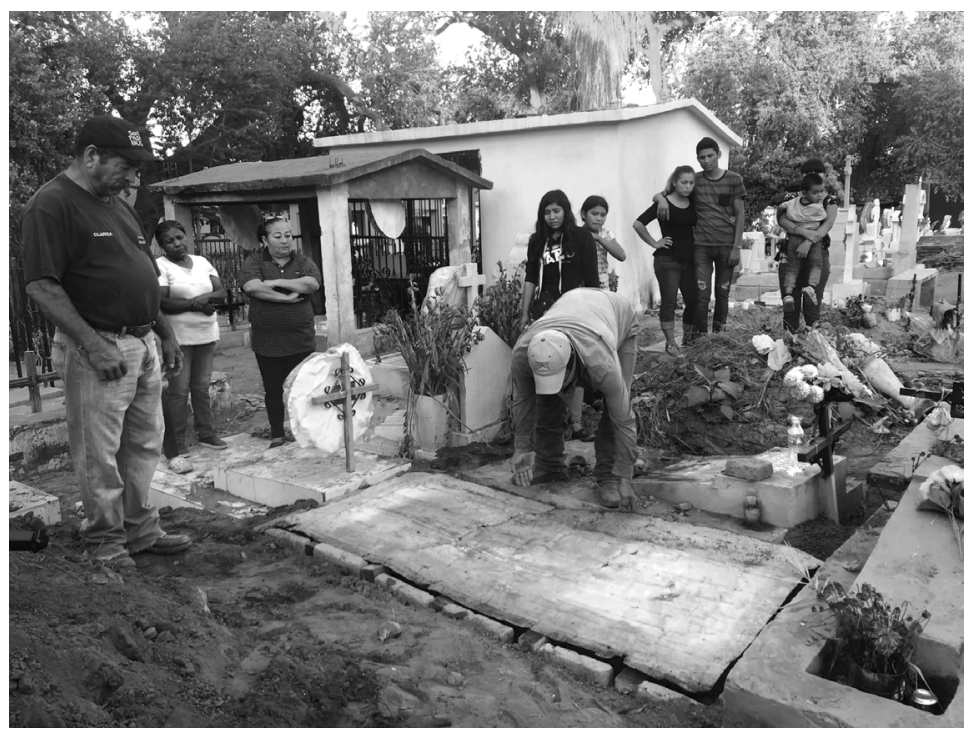

ı. En la comunidad de San Miguel, Felipe es reintegrado a su tierra en el panteón comunitario, gracias a un ritual funerario apoyado económicamente por las buscadoras y los vecinos. Archivo propio, 2018. 
para facilitar la restitución a sus familias. Pasaron meses para que las hermanas y la madre de Felipe recibieran la notificación del hallazgo de su cuerpo, que por fin retornará a la tierra de sus ancestros. En la comunidad de San Miguel, habitada en su mayoría por población indígena y campesina, se le ofrece a Felipe, como resultado de un gran esfuerzo colectivo, una placa con su nombre y una plancha de cemento sobre su tumba para protegerla de las inclemencias de clima, el ultraje y el olvido.

\section{[28 de noviembre de 2018, Panteón Jardines del Bosque,}

\section{Ahome, Sinaloa]}

De vuelta en el panteón municipal de Los Mochis, de donde se recuperó el cuerpo de Felipe, nos encontramos con un paisaje extraño. Sólo un muro separa este caótico régimen político con los territorios más privilegiados en donde reposa la muerte consentida.

Basta con caminar algunos metros entre la basura y los desniveles de esta necrogeografía del abandono para encontrar un paisaje completamente diferente. Pequeños kioscos que dan sombra a céspedes planos podados con cuidado; bajo aquéllos han de resguardarse del inclemente sol los deudos para visitar a sus muertos.

Ésta es la tumba de Joel Medina, expolicía municipal de Ahome señalado como responsable de más de una desaparición forzada por las madres buscadoras de esta región. Aquí también hay amor porque todo muerto tiene quien lo llora; hay cuidado y hay una extensión del poder y de la clase en cada detalle con la que se embellece el espacio.

Este sistema de clasificación social de la muerte remite a un tipo de apartheid funerario ${ }^{21}$ que establece diferencias profundas entre unos muertos y otros. Quienes son inhumados en las fosas clandestinas o en las fosas comunes del estado no solo son excluidos de la comunidad de los vivos, sino también de la comunidad de los muertos.

\footnotetext{
${ }^{21}$ Rousseau, "Identificación política”, op. cit., pp. 163-190.
} 


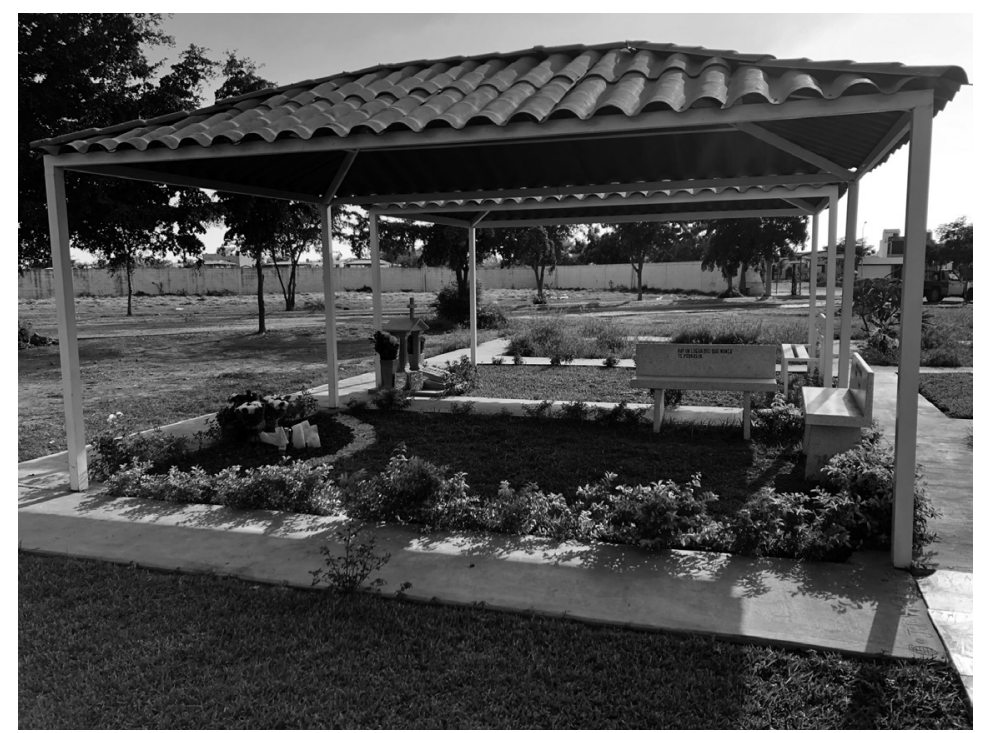

I I. A tan sólo 20 metros de las fosas de los no identificados, y separadas por un muro, se encuentran estas construcciones en donde reposan los cuerpos privilegiados del panteón.

El tratamiento radicalmente diferenciado de los cuerpos materializa la segregación: mientras unos son abandonados al árbitro de la naturaleza y a la fuerza destructora del poder de dar muerte, otros son honrados y recordados como una pérdida.

Joel Medina recibió 30 impactos de bala el 25 de febrero de 2018 y en su sepelio se le despidió con los honores de un policía destacado. Durante toda la noche el día de su muerte se escucharon detonaciones de armas de fuego que, según me explicaron Las Buscadoras, son una forma común de despedir a los muertos, sean "malandros" o sean policías.

Durante el apartheid sudafricano, comenta Nicky Rousseau, ${ }^{22}$ la población negra que moría en emboscadas o escaramuzas era ingresada al registro legal de administración de la muerte y enterrada en cementerios locales por funerarias privadas designadas

${ }^{22}$ Ibidem, p. 171.

190 / Carolina Robledo Silvestre 
por el Estado. En vez de hacer uso de fosas clandestinas, el régimen racial utilizó los panteones para desaparecer los cuerpos considerados incómodos.

Los cadáveres de las personas negras eran enterrados en ataúdes con fondos desmontables, y a veces se inhumaban hasta cuatro en una fosa, aunque estaba prohibido. Tampoco se consideraba la intervención de un clérigo, como sí se hacía en el caso de los cuerpos blancos no reclamados. "Los entierros de los pobres eran vistos con desprecio" 23 y de manera intencional se les negaba su carácter sagrado.

\section{LAS COMUNIDADES FUNERARIAS}

En Sudáfrica las mujeres empezaron a recuperar los cuerpos inhumados sin identificar en los panteones, y crearon sociedades funerarias como un medio para rescatarlos de los estragos del apartheid. También en Sinaloa Las Buscadoras se han constituido en una comunidad funeraria que garantiza un tratamiento sagrado a los cuerpos abandonados.

Estas comunidades acompañan a los deudos, proporcionan fondos para los gastos funerarios y participan de los rituales mortuorios. Son, al final, una expresión política que rescata cuerpos de los estragos del régimen de desigualdad radical, revirtiendo el ignominioso y anónimo entierro clandestino, y reestableciendo la calidad de persona de quienes yacían en el abandono de la muerte no escrita.

Además de disputar las formas soberanas del tratamiento de la muerte, las comunidades funerarias redimen la condición social de los cuerpos abandonados y recuerdan que el dańo no se causa nada más a un individuo, sino a una comunidad, y que sólo en comunidad puede resarcirse.

\section{${ }^{23} \mathrm{Idem}$.}




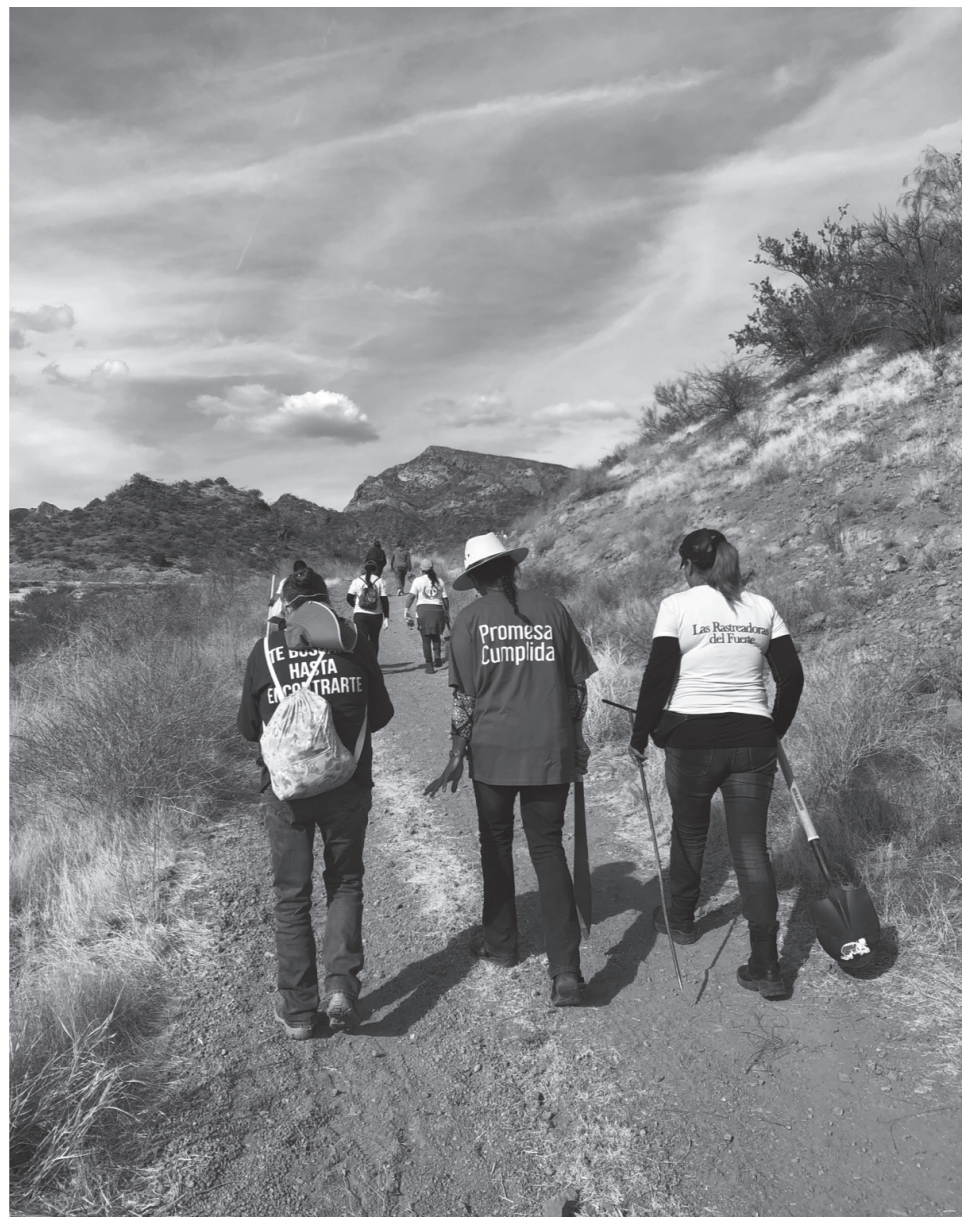

I2. Miércoles y domingo de cada semana las buscadoras salen a recorrer predios para encontrar a sus tesoros, incluso aquellas que ya han encontrado a los suyos acompañan estas jornadas con una camiseta verde que dice "Promesa Cumplida”. Archivo propio, 2018.

Con esto, confrontan la intención desarticuladora de la violencia rehabilitando las emociones y las pasiones en una política de los afectos, que tiene como soporte fundamental el cuerpo y la vincularidad. 
A pesar del terror que impone la desaparición forzada como forma de gobernanza en México, acciones colectivas como la búsqueda, la exhumación y el cuidado de los muertos ofrecen la posibilidad de reafirmar una contrageografía de los afectos.

Estas prácticas de cuidado son también una forma de sostener la humanidad en medio del terror. Por una parte, al reafirmar la contabilidad de lo que quiere ocultarse: allí está lo que ha sido desaparecido; y por otro lado, al regresar la dignidad a las personas que una vez identificadas recuperan el reconocimiento moral de su comunidad. Se trata, al final, de un trabajo de "re-membrar", de recomponer las piezas, de poner en su lugar a los muertos, de reordenar el mundo devastado por la violencia de su muerte.

El ritual funerario, juega un papel fundamental en este campo de cuidados. Aunque por lo general se ve a los ritos y a las creencias como formas de conservar la tradición, lo cierto es que son espacios potencialmente disruptivos de la normalidad, pues permiten reajustar los símbolos culturales en torno a aquello que ha quedado al margen.

Así, en el cuidado de los muertos hay una posibilidad transformadora en potencia que permitir tejer una organización convocada por la fuerza de los afectos, una fuerza inconforme y adolorida, que no se rinde. 㷛

BiBLIOGRAFÍA

Douglas, Mary. Pureza y peligro. Un análisis de los conceptos de contaminación y tabú, Madrid, Siglo XXI Editores, 1973.

Haraway, D. Ciencia, cyborgs y mujeres. La reinvención de la naturaleza. Madrid, Cátedra. 1995.

—.Modest_Witness@Second_Millennium.FemaleMan_Meets_OncoMouse: Feminism and Technoscience, Nueva York/Londres, Routledge, 1997.

Jugo, Admir y Sari Wastell. "Desensamblar los pedazos, ensamblar lo social: las vidas forenses y políticas de las fosas comunes secundarias en Bos- 
nia y Herzegovina”, en Sévane Garibian, Élisabeth Ansett y Jean-Marc Dreyfus, Restos humanos e identificación. Violencia de masa, genocidio y el "giro forense", Buenos Aires, Miño y Dávila, 2017, pp. 135-162.

Méndez Sáinz, Eloy. "De anti-lugares, o la difusión de la narco arquitectura en Culiacán”, URBS: Revista de Estudios Sociales y Ciencias Urbanas, vol. 2, núm. 2, 2012, pp. 43-62.

Panizo, Laura. "Cuerpos desaparecidos. La ubicación ritual de la muerte desatendida”, en Cecilia Hidalgo (comp.), Etnografias de la muerte. Rituales, desapariciones, VIH/SIDA y resignificación de la vida, Argentina, ClaCso, 2010, pp. 17-40.

Pita, María Victoria. Formas de morir y formas de vivir. El activismo contra la violencia policial, Buenos Aires, Editores del Puerto, 2010.

Ríos de la Torre, Guadalupe. "José Guadalupe Posada. Un cronista de la época porfiriana", Tema y Variaciones de Literatura, 28, 2007, pp. 107119.

Rosaldo, Renato. Cultura y verdad. Nueva propuesta de análisis social, México, Grijalbo, 1989.

Rousseau, Nicky. "Identificación política, disciplinas: personas desaparecidas y esqueletos coloniales en África del Sur”, en Sévane Garibian, Élisabeth Ansett y Jean-Marc Dreyfus, Restos humanos e identificación. Violencia de masa, genocidio y el "giro forense", Buenos Aires, Miño y Dávila, 2017, pp. 163-190.

Sévane Garibian, Élisabeth Ansett y Jean-Marc Dreyfus. Restos humanos e identificación. Violencia de masa, genocidio y el "giro forense", Buenos Aires, Miño y Dávila, 2017.

Spinoza, Baruch. Ética demostrada según el orden geométrico, Madrid, Ediciones Orbis, 1980.

Stepputat, Finn. Governing the Dead: Sovereignty and the Politics of Dead Bodies, uK, Manchester University Press, 2014.

Willis, G. Denyer. "The Potter's Field", Comparative Studies in Society and History, 60(3), pp. 539-568. doi:10.1017/S001041751800018X. 2018. Ziegler, Jean. Los vivos y la muerte, México, Siglo XXI Editores, 1976. 